\title{
Carbon's Three-Center, Four-Electron Tetrel Bond, Treated Experimentally
}

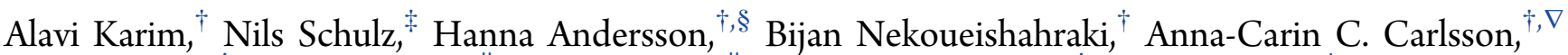 \\ Daniel Sarabi, ${ }^{\dagger}$ Arto Valkonen, Kari Rissanen, ${ }^{\| \bullet}$ Jürgen Gräfenstein, ${ }^{\dagger}$ Sandro Keller, ${ }^{\perp}\left({ }^{\circ}\right.$ \\ and Máté Erdélyi* ${ }^{\dagger} \dagger, \S, \bigcirc_{0}$
}

${ }^{\dagger}$ Department of Chemistry and Molecular Biology, University of Gothenburg, SE-412 96 Gothenburg, Sweden

${ }^{\ddagger}$ Faculty of Chemistry and Biochemistry, Organic Chemistry I, Ruhr-Universität Bochum, Universitätsstraße 150, 44801 Bochum, Germany

${ }^{\S}$ Department of Chemistry-BMC, Uppsala University, SE 75120 Uppsala, Sweden

"Department of Chemistry, University of Jyvaskyla, P.O. Box. 35, FI-40014 Jyväskylän yliopisto, Finland

${ }^{\perp}$ Molecular Biophysics, Technische Universität Kaiserslautern (TUK), 67663 Kaiserslautern, Germany

OThe Swedish NMR Centre, Medicinaregatan 5, SE-413 90 Gothenburg, Sweden

Supporting Information

ABSTRACT: Tetrel bonding is the noncovalent interaction of group IV elements with electron donors. It is a weak, directional interaction that resembles hydrogen and halogen bonding yet remains barely explored. Herein, we present an experimental investigation of the carbon-centered, three-center, four-electron tetrel bond, $[\mathrm{N}-\mathrm{C}-$ $\mathrm{N}]^{+}$, formed by capturing a carbenium ion with a bidentate Lewis base. NMRspectroscopic, titration-calorimetric, and reaction-kinetic evidence for the existence and structure of this species is reported. The studied interaction is by far the strongest tetrel bond reported so far and is discussed in comparison with the analogous halogen bond. The necessity of the involvement of a bidentate Lewis base in its formation is demonstrated by providing spectroscopic and crystallographic evidence that a monodentate Lewis base induces a reaction rather than stabilizing the tetrel bond complex. A vastly decreased Lewis basicity of the bidentate ligand or reduced Lewis acidity of the carbenium ion weakens - or even prohibits - the formation of the tetrel bond complex, whereas synthetic modifications facilitating attractive orbital overlaps promote it. As the geometry of the complex resembles the $S_{N} 2$ transition state, it provides a model system for the investigation of fundamental reaction mechanisms and chemical bonding theories.

\section{INTRODUCTION}

Noncovalent interactions are receiving vastly increasing interest. Over the past decade, the hydrogen bond has been redefined, ${ }^{1}$ and the analogous halogen, ${ }^{2}$ pnictogen, ${ }^{3}$ chalcogen, ${ }^{4,5}$ aearogen, ${ }^{6}$ and coinage-metal ${ }^{7}$ bonds have been categorized $^{8,9}$ as either $\sigma$-hole ${ }^{10}$ or E-bond interactions. ${ }^{7}$ These interactions, $\mathrm{Z}-\mathrm{X} \cdots \mathrm{Y}$, are typically observed between a Lewis base, $Y$, and a region of positive electrostatic potential on atom $\mathrm{X}$, being an electrophile connected to atom $\mathrm{Z}$, along the extension of the $\mathrm{Z}-\mathrm{X}$ bond. The stronger the interaction, the shorter and more directional the $\mathrm{X}-\mathrm{Y}$ bond is and the longer the $\mathrm{Z}-\mathrm{X}$ bond is. When the Lewis basicity of the atoms $\mathrm{Z}$ and $\mathrm{Y}$ are closely matched $(\mathrm{Z} \approx \mathrm{Y})$, the central electrophilic atom $X$ is equally shared between them, and accordingly the $\mathrm{Z}-\mathrm{X}$ and $\mathrm{X}-\mathrm{Y}$ bonds are equally strong and equally long. These interactions were described as three-center, fourelectron bonds. ${ }^{11}$ With a proton being the electrophilic atom $(\mathrm{X}=\mathrm{H})$, this special bond $(\mathrm{Y}-\mathrm{X}-\mathrm{Y})$ is commonly termed a "low-barrier", a "short", or a "strong" hydrogen bond. ${ }^{12}$ The low-barrier $\mathrm{N}-\mathrm{H}-\mathrm{N}$ and $\mathrm{O}-\mathrm{H}-\mathrm{O}$ hydrogen bonds received great interest, as they were proposed to be extra strong-up to $\sim 125 \mathrm{~kJ} / \mathrm{mol}$ - and accordingly to stabilize transition states and intermediates, for example, in enzyme-catalyzed reactions. $^{13,14}$ Their true nature and geometry, however, remains the subject of intense debates. ${ }^{15^{-17}}$ The analogous $\mathrm{Y}-\mathrm{X}-\mathrm{Y}$ halogen bond is static and symmetric, both in solutions and in the solid state, and possesses a partial covalent character. ${ }^{18-23}$ Whereas conventional halogen bonds, $\mathrm{R}-\mathrm{X} \cdots \mathrm{Y}$, are up to $\sim 40$ $\mathrm{kJ} / \mathrm{mol}$ energy, the three-center, four-electron halogen bonds are significantly stronger, $120-150 \mathrm{~kJ} / \mathrm{mol}^{19,21}$ Due to its exceptional strength, the three-center $\mathrm{N}-\mathrm{I}-\mathrm{N}$ halogen bond is applicable for stabilization of intricate complex supramolecular complexes, for instance. ${ }^{24-26}$ The noncovalent interactions in which tetrel elements, i.e., those belonging to group IV of the periodic system, act as electrophiles are typically very weak,

Received: September 4, 2018

Published: November 28, 2018 
$<10 \mathrm{~kJ} / \mathrm{mol}^{27}$ Both computational and experimental evidence is available for the lightest tetrel element, carbon, forming tetrel bonds. ${ }^{28-30}$ Complexes possessing a three-center, fourelectron tetrel bond with carbon acting as the electrophilic center correspond to a pentacoordinate configuration ${ }^{11}$ that is commonly referred to as an "activated complex" or "transition state". This labile geometry ${ }^{31}$ involves a trigonal bipyramidal carbon with three of its substituents situated in one plane, while the incoming nucleophile and leaving group are positioned apically in a linear three-center, four-electron tetrel bond. Among other reactions, the classical bimolecular nucleophilic substitution $\left(\mathrm{S}_{\mathrm{N}} 2\right)$ passes through this highenergy configuration, as discussed in virtually every undergraduate textbook. The carbon tetrel bond has been suggested to play a critical role in directing $S_{N} 2$ reactions. ${ }^{32}$ Because of its fundamental importance, the generation of model compounds allowing the experimental investigation of this carbon configuration has raised vast interest. All model systems so far explored experimentally are intramolecular ${ }^{33-40}$ and possess two intramolecular electron-donor functionalities geometrically forced into the apical positions of the electrophilic carbon, trapping it in a (pseudo)pentacoordinate configuration. ${ }^{34-39,41,42}$

By contrast, the investigation of intermolecular complexes that require formation of a thermodynamically stable threecenter, four-electron tetrel bond, allowing dissociation or smooth adjustment of bond distances and angles for a stable geometry, has so far lagged behind. Herein, we present the first intermolecular three-center, four-electron tetrel bond complex possessing a carbon as the central electrophile, as well as its investigation in solution.

Lately, the analogy of the three-center, four-electron tetrel bond of carbons ${ }^{38}$ to those of the isoelectronic halogen bond, such as that of the central halogen of the triiodide ion, [ $\mathrm{I} \cdots \mathrm{I} \cdots$ $\mathrm{I}]^{-, 42,43}$ and of $[\mathrm{N} \cdots \mathrm{X} \cdots \mathrm{N}]^{+}$complexes $^{18,19,23}$ has been recognized. ${ }^{11,44-47}$ The three-center halogen bond of $[\mathrm{N} \cdots$ $\mathrm{X} \cdot \mathrm{N}]^{+}$complexes is formed by the donation of two unshared electrons of the nitrogens into the "p-holes", that is, the two lobes of the vacant p-orbital of the halogen(I) (Figure 1). ${ }^{48}$ These $\mathrm{p}$-holes are analogous to the electron depleted $\sigma$-hole that gives rise to the formation of classical halogen, chalcogen, pnictogen, and tetrel bonds. ${ }^{49}$ Whereas the three-center, fourelectron halogen bond complexes have been assessed experimentally, the corresponding compounds encompassing three-center, four-electron tetrel bonds have so far been studied in silico, ${ }^{41,47}$ but rarely under standard laboratory conditions in solution. ${ }^{37,38}$ The molecular system studied here resembles the one we previously applied for the assessment of the isoelectronic halogen bond. ${ }^{18,19}$ Similar to the cationic halogen, $\mathrm{X}^{+}$, held in position by two $\mathrm{N}-\mathrm{X}$ halogen bonds, the carbenium carbon, $\mathrm{C}^{+}$, of $\mathbf{1 a}-\mathbf{f}$ (Figures 1 and 2) has an empty p-orbital capable of simultaneously forming two N-C bonds upon overlapping with the nonbonding orbital of the two nitrogen donors that are positioned at optimal distance and in an ideal orientation provided by $\mathbf{2} \mathbf{a}-\mathbf{c}$. This orbital overlap is expected to yield two bonds possessing a partial covalent character. $^{19,23,48}$ The resulting complex (3a-f, Figure 2) ought to have a three-center, four-electron $[\mathrm{N} \cdots \mathrm{C} \cdots \mathrm{N}]^{+}$tetrel bond and a trigonal bipyramidal geometry, analogous to that of the transition state of $\mathrm{S}_{\mathrm{N}} 2{ }^{39}$ Here, we present the synthesis, solution NMR-spectroscopic, calorimetric, and kinetic investigations of the intermolecular tetrel bond complexes 3 .

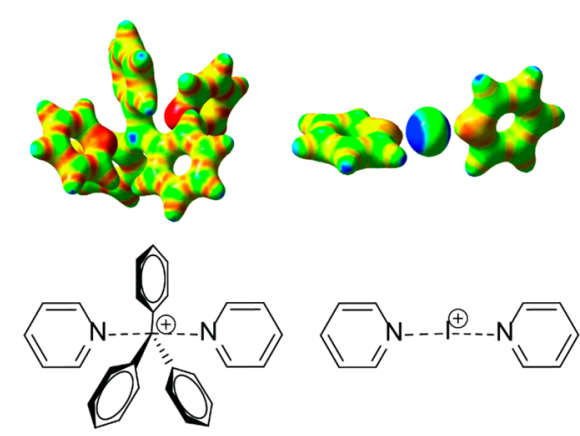

Figure 1. Three-center, four-electron bond, $[\mathrm{N} \cdots \mathrm{C} \cdots \mathrm{N}]^{+}$, of a hypercoordinate carbon (left) resembles the isoelectronic threecenter halogen bond, $[\mathrm{N} \cdots \mathrm{X} \cdots \mathrm{N}]^{+}$(right). The empty p-orbital of the central atom of both complexes possesses two electrophilic regions (blue) that simultaneously receive electrons from two Lewis bases (red), the nonbonding orbitals of two complexing pyridines. The structures shown are [bis(pyridine)triphenylcarbenium $]^{+}$(left) and $[\text { bis(pyridine)iodine }]^{+}$(right) and are illustrated with their colorcoded electrostatic potential mapped on the electron isodensity surface at a contour value of 0.09 electron $\mathrm{Bohr}^{-3}$. The color ramp indicates the most negative potential in red $(0.3 \mathrm{au})$ and the most positive potential in blue $(0.85 \mathrm{au})$.

\section{RESULTS AND DISCUSSION}

Synthesis. 1,2-Bis(pyridin-2-ylethynyl)benzenes 2a-c were synthesized following a published procedure. ${ }^{21}$ Pyridine, 4-picoline, 1a, and 1f were commercially available, whereas $\mathbf{1 d}$ and 1e were synthesized from their triaryl alcohol and triaryl halide precursors, respectively (Supporting Information). ${ }^{50}$ To generate complexes $\mathbf{3 a}-\mathbf{f}$ (Figure 2 and Table 1 ), $\mathbf{1 a}-\mathbf{f}$ and ligands $2 a-c(1: 1)$ were mixed at room temperature under dry conditions in an NMR tube, using dry $\mathrm{CD}_{2} \mathrm{Cl}_{2}$ as solvent. For the generation of $\mathbf{5 b}-\mathbf{c}$ (Figure 2 and Table 1), 2 equiv of dry pyridine or picoline were added to the $\mathrm{CD}_{2} \mathrm{Cl}_{2}$ solution of triphenylcarbenium tetrafluoroborate, 1 a.

Structure Elucidation. As ${ }^{15} \mathrm{~N}$ NMR has an inherently wide chemical shift range of $\sim 800 \mathrm{ppm}$, it is expected to provide large, easy-to-detect chemical shift changes upon formation of weak molecular complexes in which a nitrogen acts as a Lewis base. ${ }^{22,48,51}$ Accordingly, $\sim 100$ ppm ${ }^{15} \mathrm{~N}$ NMR coordination shifts, $\Delta \delta^{15} \mathrm{~N}_{\text {coord }}$, have been reported for formation of $\left[\mathrm{N} \cdots[\cdots \mathrm{N}]^{+}\right.$halogen-bonded complexes. ${ }^{18,19,21,23}$ Following literature conventions, ${ }^{21} \Delta \delta_{\text {coord }}$ is defined as the chemical shift difference of the complex and the free ligand, that is, $\Delta \delta_{\text {coord }}=\delta_{\text {complex }}-\delta_{\text {ligand }}$. Because of its proven applicability, ${ }^{15} \mathrm{~N}$ NMR was applied here as the primary tool to detect analogous $[\mathrm{N} \cdots \mathrm{C} \cdots \mathrm{N}]^{+}$tetrel bond complexes (Table 1). The observation of a single set of ${ }^{15} \mathrm{~N} N M R$ signals for $3 a-$ $f$ suggests the formation of complexes in which the carbenium carbon is equally bound to both Lewis basic nitrogens (Table 1 and Figure 3). Accordingly, the ${ }^{15} \mathrm{~N}$ NMR chemical shift change observed on the bidentate ligand is accompanied by a large ${ }^{13} \mathrm{C}$ NMR chemical shift change of the carbenium carbon (Table 1) of the interaction partner, thus supporting the formation of a $[\mathrm{N} \cdots \mathrm{C} \cdots \mathrm{N}]^{+}$three-center, four-electron tetrel bond in $3 \mathbf{a}-\mathbf{d}$, while revealing the formation of no, or very weak, complexes for $3 \mathbf{e}-\mathbf{f}$. The observed ${ }^{15} \mathrm{~N}$ complexation shifts, $\Delta \delta^{15} \mathrm{~N}_{\text {coord, }}$ are comparable in magnitude yet are somewhat smaller than those observed for the isoelectronic halogen-bonded compounds. ${ }^{19,21-23}$

Upon mixing 1a with 1,2-bis(phenylethynyl)benzene, an analogue of $2 \mathrm{c}$ lacking any Lewis basic nitrogen, no ${ }^{13} \mathrm{C}$ NMR 


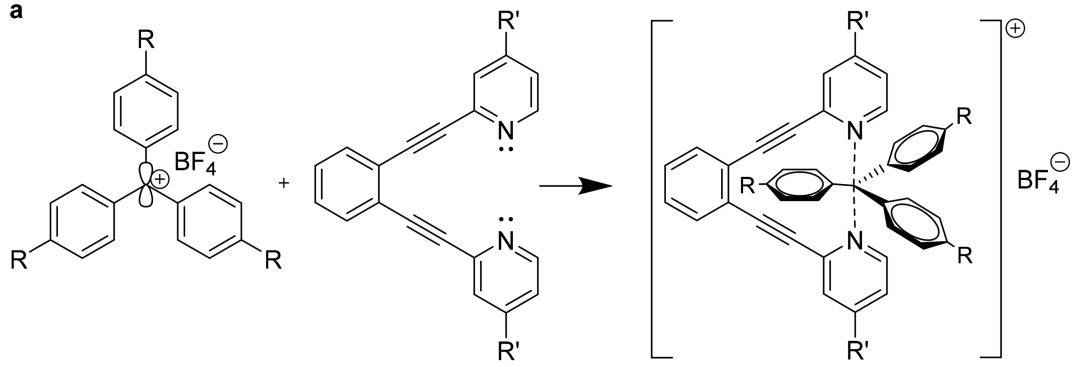

1a-f<smiles>O=C(c1ccccc1)c1ccccc1Oc1ccccc1</smiles>

$1 \mathrm{a}$ 2a-c<smiles>[R]c1ccncc1</smiles>

4b-c 3a-f

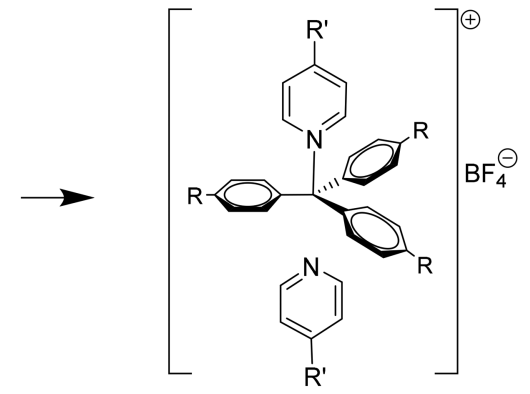

$5 b-c$

Figure 2. Synthesis of complexes $3 \mathbf{a}-\mathbf{f}$ and $\mathbf{5 b}-\mathbf{c}$. For all compounds, $\mathrm{R}=\mathrm{H}(\mathrm{a}-\mathrm{c}), \mathrm{Me}(\mathrm{d}), \mathrm{OMe}(\mathrm{e}), \mathrm{NMe}_{2}(\mathrm{f}), \mathrm{R}^{\prime}=\mathrm{CF}_{3}(\mathrm{a}), \mathrm{Me}(\mathrm{b})$, and $\mathrm{H}(\mathrm{c}-$ f). Hence, $3 a(1 a+2 a), 3 b(1 a+2 b), 3 c(1 a+2 c), 3 d(1 d+2 c), 3 e(1 e+2 c), 3 f(1 f+2 c), 5 b(1 a+4 b)$, and $5 c(1 a+4 c)$. Conditions: The compounds were mixed in dry $\mathrm{CD}_{2} \mathrm{Cl}_{2}$ at room temperature in an NMR tube. The structure of $3 a-f$ is not necessarily its preferred conformation.

Table $1 .{ }^{15} \mathrm{~N}$ and ${ }^{13} \mathrm{C}$ NMR Chemical Shifts ${ }^{a}$ and Coordination Shifts (ppm) of $[\mathrm{N} \cdots \mathrm{C} \cdots \mathrm{N}]^{+}$Tetrel Bond Complexes

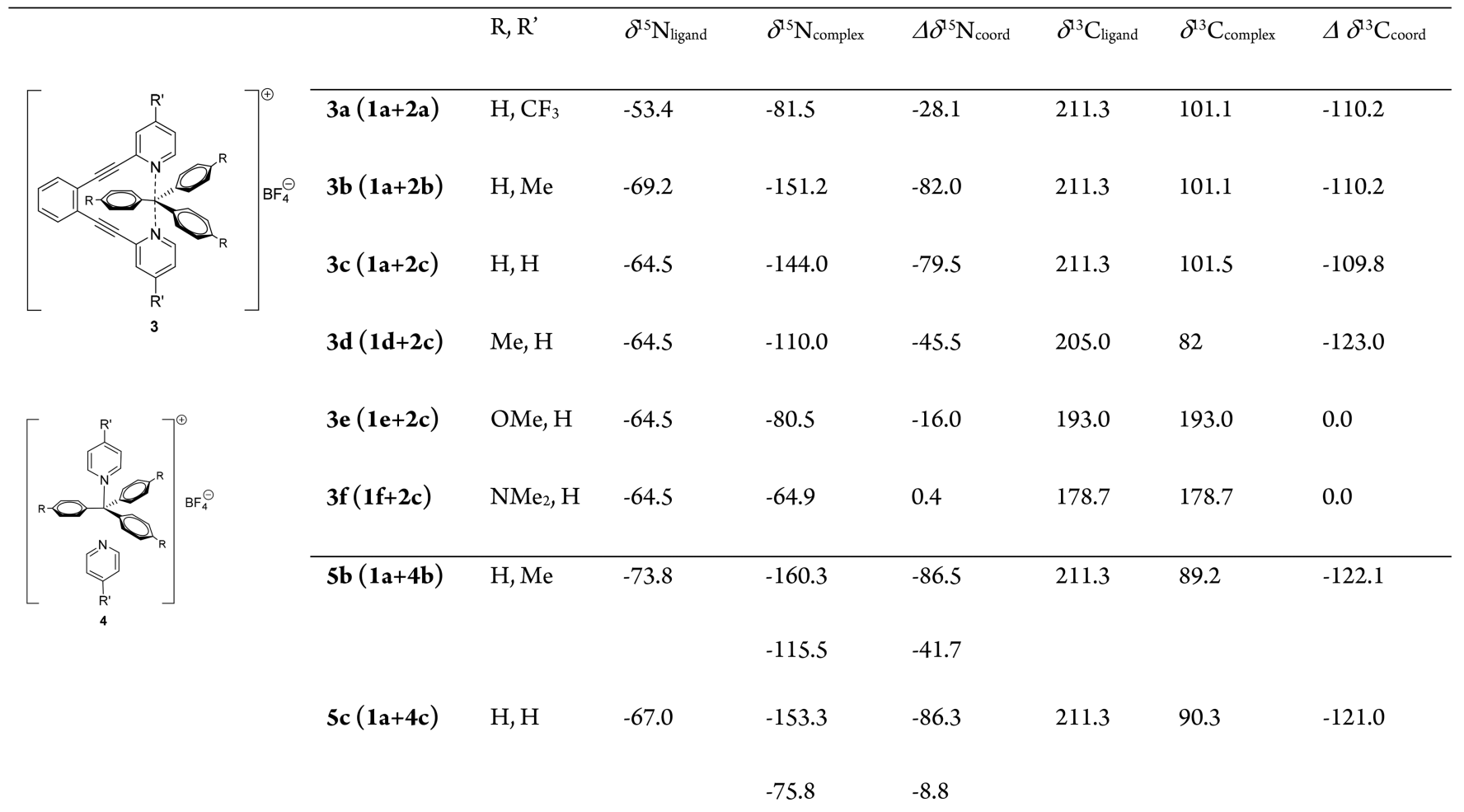

${ }^{a 15} \mathrm{~N}$ NMR shifts were referenced to $\mathrm{CH}_{3} \mathrm{NO}_{2}(0 \mathrm{ppm})$ using a closed capillary. ${ }^{51}$

chemical shift alteration on 1a could be observed (Figure S1, Supporting Information), corroborating that the interaction seen for $\mathbf{3} \mathbf{a}-\mathbf{f}$ involves the nitrogens. As an additional control to confirm the involvement of the trityl carbon in the interaction responsible for the formation of $3 a-f$, the ${ }^{15} \mathrm{~N}$
NMR shift of $2 \mathrm{c}$ was measured in the presence of tri-ptolylmethanol. This resulted in no nitrogen chemical shift alteration of 2c (Figure S2, Supporting Information). The two control experiments confirm that the large $\Delta \delta^{15} \mathrm{~N}_{\text {coord }}$ and $\Delta \delta^{13} \mathrm{C}_{\text {coord }}$ observed for $3 \mathrm{c}$ cannot be due to moisture-induced 


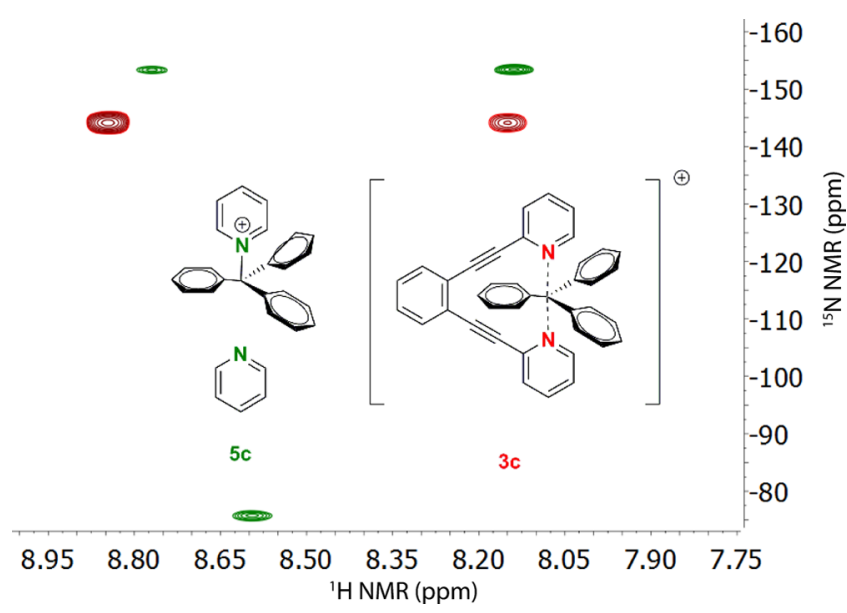

Figure 3. Superimposed ${ }^{15} \mathrm{~N}$ HMBC spectra of complexes $3 \mathrm{c}$ (red) and $5 \mathrm{c}$ (green) acquired in $\mathrm{CD}_{2} \mathrm{Cl}_{2}$ solution at $25{ }^{\circ} \mathrm{C}$. Whereas $3 \mathrm{c}$ shows a single set of ${ }^{15} \mathrm{~N}$ NMR signals, suggesting equally strong coordination of the carbenium ion to both nitrogens, $5 c$ has an asymmetric structure with a strongly and a weakly coordinating nitrogen revealed by two sets of signals. Note that the structure drawn for $3 \mathrm{c}$ is not necessarily its most stable conformation.

decomposition of 1a and subsequent hydrogen bonding of triphenylmethanol to $2 \mathrm{c}$.

Whereas bidentate ligands $\mathbf{2 a}-\mathbf{c}$ promote formation of a symmetric $[\mathrm{N} \cdots \mathrm{C} \cdots \mathrm{N}]^{+}$complex, or possibly a rapidly equilibrating pair of asymmetric $[\mathrm{N}-\mathrm{C} \cdots \mathrm{N}]^{+} \rightleftarrows[\mathrm{N} \cdots \mathrm{C}-\mathrm{N}]^{+}$ complexes, ${ }^{52}$ the monodentate Lewis bases pyridine and picoline form asymmetric ion pairs with 1 a as indicated by the observation of two sets of ${ }^{15} \mathrm{~N}$ NMR chemical shifts for $\mathbf{5 b}-\mathbf{c}$ (Table 1 and Figure 3 ). The coordination shifts, $\Delta \delta^{15} \mathrm{~N}_{\text {coord }}$, of the latter complexes suggest that one nitrogen forms a strong, presumably covalent, bond to the carbenium carbon of 1a, whereas the other nitrogen is involved in a weaker secondary interaction. This hypothesis was corroborated by the identification by single-crystal X-ray diffraction of 1-tritylpyridin-1-ium tetrafluoroborate crystals (CCDC 1581474 ), formed from the $\mathrm{CD}_{2} \mathrm{Cl}_{2}$ solution of 5c (Figure 4). Hence, the bidentate Lewis base $2 \mathrm{c}$ stabilizes the reactive

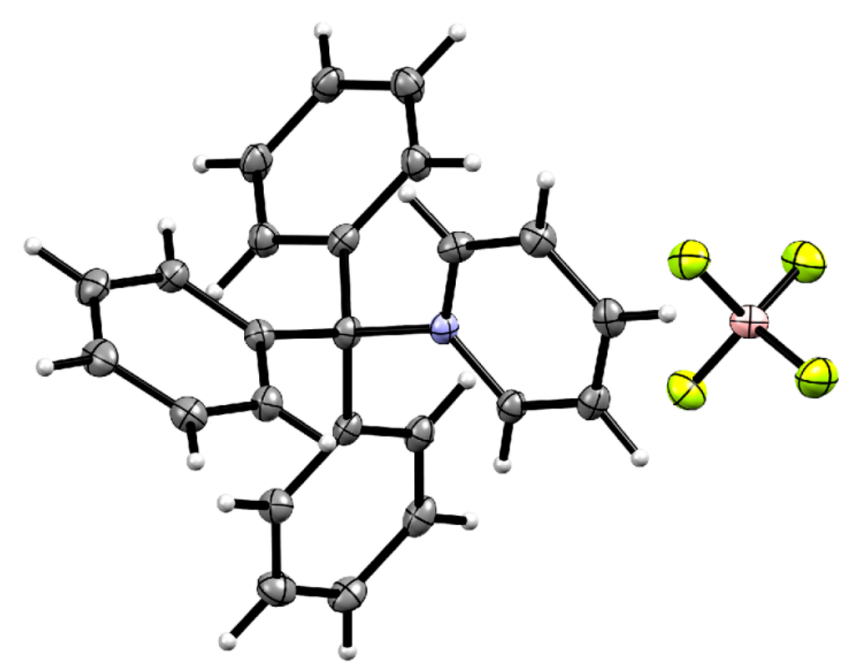

Figure 4. Molecular structure of 1-tritylpyridin-1-ium tetrafluoroborate. The thermal displacement parameters are shown at the $50 \%$ probability level. carbenium ion 1a, whereas its monodentate analogue, pyridine, undergoes $N$-alkylation with the electrophile. The $\delta^{15} \mathrm{~N}-144.0$ $\mathrm{ppm}$ of $3 \mathrm{c}$ indicates a strong $\mathrm{N}-\mathrm{C}$ bond, which is close in chemical shift to that of the covalently functionalized pyridine of $5 \mathrm{c}\left(\delta^{15} \mathrm{~N}-153.3 \mathrm{ppm}\right)$. Strong complexation for $3 \mathrm{c}$ was supported by the comparable translational diffusion coefficients of $1 \mathrm{a}\left(11.5 \times 10^{-10} \mathrm{~m}^{2} \mathrm{~s}^{-1}\right)$ and $2 \mathrm{c}\left(13.8 \times 10^{-10} \mathrm{~m}^{2}\right.$ $\mathrm{s}^{-1}$ ) of the complex. The diffusion coefficients of $1 \mathrm{a}$ and one of the pyridines $\left(\Delta \delta^{15} \mathrm{~N}_{\text {coord }}-86.3 \mathrm{ppm}\right)$ of complex 5c are similar $\left(9.8 \times 10^{-10}\right.$ and $\left.9.4 \times 10^{-10} \mathrm{~m}^{2} \mathrm{~s}^{-1}\right)$, indicating that these are connected, whereas the second weakly complexing pyridine $\left(\Delta \delta^{15} \mathrm{~N}_{\text {coord }}-8.8 \mathrm{ppm}\right)$ has a diffusion coefficient $\left(25.6 \times 10^{-10} \mathrm{~m}^{2} \mathrm{~s}^{-1}\right)$ that indicates that this pyridine moves independently of $\mathbf{1 a}$ in solution.

Dynamics. Compounds $3 \mathrm{a}-\mathrm{c}$ might be involved in a bellclapper-type rearrangement; ${ }^{38}$ that is, instead of being present as static and symmetric $[\mathrm{N} \cdots \mathrm{C} \cdots \mathrm{N}]^{+}$tetrel bond complexes, they might exist in solution as dynamic mixtures of rapidly exchanging complexes possessing a covalent $\mathrm{C}-\mathrm{N}$ bond and a pyridine weakly connected through a conventional $\mathrm{C} \cdots \mathrm{N}$ tetrel bond, $[\mathrm{N}-\mathrm{C} \cdots \mathrm{N}]^{+} \rightleftarrows[\mathrm{N} \cdots \mathrm{C}-\mathrm{N}]^{+}$. To differentiate between the possibilities of a static and symmetric complex versus a mixture of rapidly interconverting, weakly coordinating ones, we followed the standard procedures of the field, ${ }^{38}$ acquiring ${ }^{1} \mathrm{H}$ and ${ }^{13} \mathrm{C}$ NMR and ${ }^{1} \mathrm{H},{ }^{15} \mathrm{~N}$ HMBC spectra for $3 \mathbf{d}$ at various temperatures. Both the static and dynamic geometries are expected to show a single sharp set of NMR signals at higher temperatures. A single set of signals is expected to remain detectable also at low temperature for a static $[\mathrm{N} \cdots \mathrm{C} \cdots \mathrm{N}]^{+}$ tetrel bond complex, whereas for a dynamic mixture of asymmetric structures, two sets of signals, or at least significant signal broadening, is expected. ${ }^{38}$ We observed a single sharp set of ${ }^{1} \mathrm{H},{ }^{13} \mathrm{C}$, and ${ }^{15} \mathrm{~N}$ NMR signals at all temperatures, including at $-40{ }^{\circ} \mathrm{C}$ (Figures S3-S5, Supporting Information). This observation is best compatible with a static and symmetric geometry, even if it cannot fully exclude a very low barrier $[\mathrm{N}-\mathrm{C} \cdots \mathrm{N}]^{+} \rightleftarrows[\mathrm{N} \cdots \mathrm{C}-\mathrm{N}]^{+}$interconversion, with an energy barrier $\Delta G^{\ddagger} \ll 38 \mathrm{~kJ} / \mathrm{mol}$ and half-life of the possible interconverting states $t_{1 / 2} \ll 6.4 \mu \mathrm{s}$, when estimated from the chemical shift difference of pyridine $\left(4 \mathrm{c}, \delta\left({ }^{15} \mathrm{~N}\right)-67 \mathrm{ppm}\right)$ and 1-tritylpyridinium ion $\left(\mathbf{5 c}, \delta\left({ }^{15} \mathrm{~N}\right)-153 \mathrm{ppm}\right)$ as model compounds for the equally populated, not exchanging free versus $\mathrm{N}$-alkylated end states, the ${ }^{15} \mathrm{~N}$ NMR observation frequency $50.67 \mathrm{MHz}$, and a coalescence temperature $<-40$ ${ }^{\circ} \mathrm{C} .{ }^{33}$ To detect a possible low-barrier interconversion, we further performed isotopic perturbation of equilibrium (IPE) NMR measurements. ${ }^{54,55}$ Similar to earlier studies of related systems, we compared the temperature dependence of the secondary deuterium isotope effects of $\mathbf{3 d}$ to those of a static reference, 2c, and of its hydrogen-bonded $[\mathrm{N}-\mathrm{H} \cdots \mathrm{N}]^{+} \rightleftarrows$ $[\mathrm{N} \cdots \mathrm{H}-\mathrm{N}]^{+}$complex used as a dynamic reference, as described in detail elsewhere. ${ }^{15,18-21,56}$ Selective deuterium labeling of $2 \mathrm{c}$ was performed at the pyridine carbon closest to the nitrogen, ${ }^{19}$ and isotope effects were collected in the temperature range 25 to $-40{ }^{\circ} \mathrm{C}$, for all pyridine carbons. Signal overlaps prohibited us from determining the temperature dependence of three- and four-bond isotope effects and, hence, from drawing a reliable conclusion from the IPE NMR study (for details, see pages S46-S48 in the Supporting Information). Overall, the variable-temperature study suggest that 3 is expectably present in solution as a static and symmetric $[\mathrm{N} \cdots \mathrm{C} \cdots \mathrm{N}]^{+}$tetrel bond complex; however, we cannot fully exclude the possibility of interconversion of 

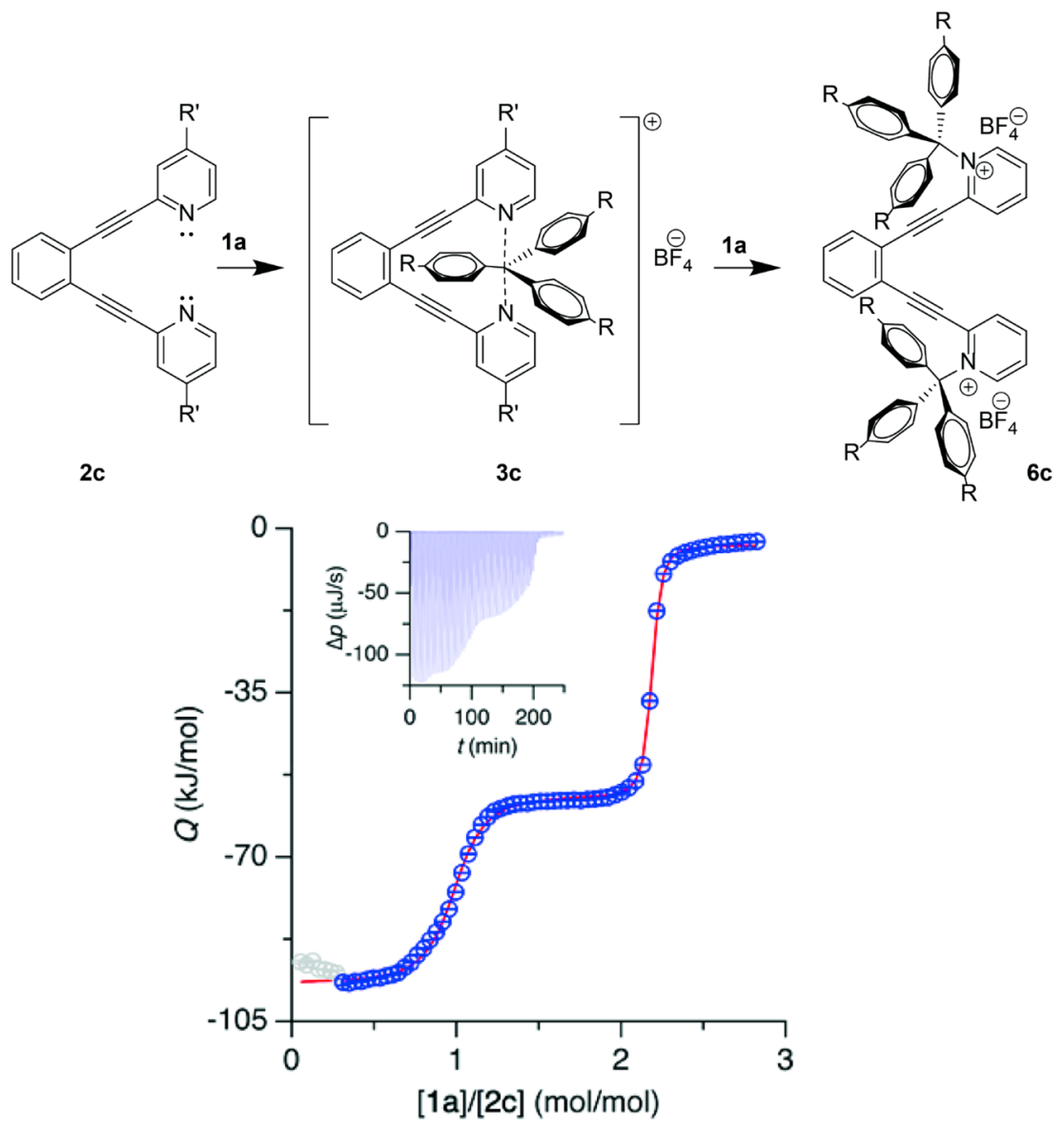

Figure 5. Titration of the bidentate ligand $2 \mathrm{c}$ with $1 \mathrm{a}$ yields the strong 1:1 complex, $3 \mathrm{c}$ (top). Upon addition of an excess of $1 \mathrm{a}$, the $1: 2$ complex of $\mathbf{1 a} / \mathbf{2 c}, \mathbf{6 c}$, is formed, as revealed by the bimodal shape of the isotherm (bottom). Isothermal titration calorimetry was performed at $25{ }^{\circ} \mathrm{C}$. Triphenylcarbenium tetrafluoroborate $1 \mathrm{a}$ at a concentration of $6.6 \mathrm{mM}$ was titrated to the bidentate ligand $2 \mathrm{c}$ at a concentration of $0.5 \mathrm{mM}$. The main panel shows the isotherm depicting normalized heats of reaction, $Q$ as a function of the $\mathbf{1 a} / \mathbf{2 c}$ molar ratio in the calorimeter cell (blue circles) along with uncertainties (blue horizontal lines) resulting from baseline assignment and peak integration. ${ }^{57}$ Nonlinear least-squares fits (red solid line) were based on the presumption of two interaction sites, ${ }^{58}$ as reflected in the bimodal shape of the isotherm. Inset: The corresponding raw thermogram displaying differential heating power, $\Delta p$, versus time, $t$. Best-fit parameter values and associated confidence intervals are summarized in the text, with the detailed analysis contained in the Supporting Information. Note that the structure drawn for $3 \mathrm{c}$ is not necessarily its most stable conformation.

analogous asymmetric $[\mathrm{N}-\mathrm{C} \cdots \mathrm{N}]^{+} \rightleftarrows[\mathrm{N} \cdots \mathrm{C}-\mathrm{N}]^{+}$geometries encompassing conventional $\mathrm{N}-\mathrm{C}$ covalent and $\mathrm{N} \cdots \mathrm{C}$ tetrel bonds.

Despite repeated attempts, the crystallization of $3 c$ and $3 d$ remained unsuccessful. It should, however, be noted that X-ray crystallography would not necessarily be able to describe the geometry of three-center tetrel bond complexes in solution. The analogous $[\mathrm{N}-\mathrm{H}-\mathrm{N}]^{+}$hydrogen bond complexes were shown to be a rapidly interconverting mixture of asymmetric geometries in solution, whereas they are static, symmetric complexes in the solid state. ${ }^{15}$ Preliminary density functional theory (DFT) calculations of 5c and 3c were unable to reproduce the experimental observations (see Supporting Information pages S51-S66 for details). This may indicate the need for higher-level computational approaches or that our structural interpretation of the NMR data is not sufficiently accurate. DFT has previously correctly predicted the geometry of an analogous asymmetric, intramolecular three-center tetrel bond complex. ${ }^{37}$ Continued experimental and computational investigations of the above and closely related molecular systems are expected to be capable of verifying or refuting the proposed structures of $3 \mathbf{a}-\mathbf{f}$.
Binding Affinity. Isothermal titration calorimetry was conducted to determine the binding strength of complex $3 \mathrm{c}$. Titration of the $\mathrm{CH}_{2} \mathrm{Cl}_{2}$ solution of $2 \mathrm{c}$ with triphenyl carbenium tetrafluoroborate, $\mathbf{1 a}$, dissolved in $\mathrm{CH}_{2} \mathrm{Cl}_{2}$, indicates the formation of a strong 1:1 complex characterized by $K_{1}=$ $1.9 \mathrm{nM}, \Delta G^{\circ}{ }_{1}=-49.8 \mathrm{~kJ} / \mathrm{mol}, \Delta H^{\circ}{ }_{1}=-93.4 \mathrm{~kJ} / \mathrm{mol}$, and $-T \Delta S^{\circ}{ }_{1}=43.7 \mathrm{~kJ} / \mathrm{mol}$. Upon addition of an excess of $1 \mathrm{a}$, a $1: 2$ (2c/1a) complex $6 \mathrm{c}$ is generated in a second, weaker binding step with $K_{2}=237 \mathrm{nM}, \Delta G^{\circ}{ }_{2}=-37.8 \mathrm{~kJ} / \mathrm{mol}, \Delta H^{\circ}{ }_{2}=-53.1$ $\mathrm{kJ} / \mathrm{mol}$, and $-T \Delta S^{\circ}{ }_{2}=15.3 \mathrm{~kJ} / \mathrm{mol}$ (Figure 5). Formation of the latter dialkylated $6 \mathrm{c}$ is in line with the smooth reaction of pyridine with triphenylcarbenium tetrafluoroborate, 1a, to form 1-tritylpyridin-1-ium tetrafluoroborate (5c). In the doubly positively charged complex $6 c$, the charge of the carbenium is presumably distributed over the entire conjugated aromatic system, akin to the analogous halogen-bonded complexes. $^{19,21}$ The formation of $6 c$ upon addition of an excess of 1a to $2 \mathrm{c}$ was also confirmed by NMR $\left(\delta^{15} \mathrm{~N}-143.7\right.$ ppm; Supporting Information, Figure S6). The free energy $\Delta G^{\circ}{ }_{1}$ of the initial complex formation results from a remarkable enthalpic contribution, which is partly offset by a substantial loss of entropy; for $6 \mathrm{c}$, both contributions are 
largely reduced in magnitude, but the reaction remains purely enthalpy-driven. A reverse titration, that is, addition of a $\mathrm{CH}_{2} \mathrm{Cl}_{2}$ solution of $2 \mathrm{c}$ into the solution of $1 \mathrm{a}$, supported the above binding model (Supporting Information).

Electron Density. Upon complexation, a considerable deshielding of the nitrogen of $2 \mathrm{a}-\mathrm{c}$ and shielding of the carbenium carbon of $\mathbf{1 a}-\mathbf{f}$ were observed. The magnitude of the observed chemical shift changes (Table 1) are expected to reflect the electron density alteration of the studied complexes, even if they do not necessarily correlate with bond strength. ${ }^{21}$ Upon decreasing the electron deficiency of the carbenium carbon, $3 \mathrm{c} \rightarrow \mathbf{f}$, smaller $\Delta \delta^{15} \mathrm{~N}_{\text {coord }}$ and $\Delta \delta^{13} \mathrm{C}_{\text {coord }}$ are detected (Table 1). This may be due to a gradual weakening of the $[\mathrm{N} \cdots$ $\mathrm{C} \cdots \mathrm{N}]^{+}$tetrel bond interaction upon decreasing the electrophilicity of the carbenium carbon.

Increasing electron density of the Lewis basic nitrogen of the bidentate ligand, $\mathbf{2 a}<\mathbf{2} \mathbf{c}<\mathbf{2} \mathbf{b}$, is associated with an increase of $\Delta \delta^{15} \mathrm{~N}_{\text {coord }}$, in the order $3 \mathrm{a}<3 \mathrm{c}<3 \mathrm{~b}$. In contrast, $\Delta \delta^{13} \mathrm{C}_{\text {coord }}$ remains virtually unaltered. The weak electron-donating effect of a 4-Me substituent does not have a vast influence on the coordination shifts as reflected by the comparable $\Delta \delta^{15} \mathrm{~N}_{\text {coord }}$ and $\Delta \delta^{13} \mathrm{C}_{\text {coord }}$ of $\mathbf{3 b}$ and $3 \mathbf{c}$ as well as $\mathbf{5 b}$ and $\mathbf{5 c}$.

Masking Lewis Acidity by Tetrel Bond Formation. Triphenyl carbenium ions are powerful Lewis acid catalysts that were used, for example, to facilitate Diels-Alder reactions. ${ }^{59}$ Such reactions do not proceed in the absence of a catalyst, while upon activation with $0.5 \mathrm{~mol} \%$ triphenylcarbenium ion, they give high conversion within $30 \mathrm{~min}$. To provide additional evidence for the participation of the carbenium p-orbital in a tetrel bond, involving an orbital interaction, we ran the Diels-Alder condensation of acrolein and cyclohexadiene (Figure 6) in the presence of 1a, 3c, and 7. Here, 7 denotes 2-((2-(phenylethynyl)phenyl)ethynyl)-1tritylpyridin-1-ium, formed upon mixing $\mathbf{1 a}$ and 2-((2(phenylethynyl)phenyl)ethynyl)pyridine (Supporting Information, page S8), a mononitrogen analogue of 3c. We monitored the progress of each reaction by acquiring the ${ }^{1} \mathrm{H}$ NMR integrals of the starting material and the product using their well-separated aldehyde protons as reporter nuclei. As shown in Figure 6, the Diels-Alder reaction progresses with secondorder rate in the presence of $1 \mathrm{a}$, whereas it does not give any conversion in the presence of $3 \mathrm{c}$ and only low conversion in the presence of 7 . This is in excellent agreement with the observation of Bah and Franzen, reporting that addition of the $\mathrm{N}$-Lewis base 2,6-di-tert-butylpyridine to 1a inhibits the DielsAlder catalytic activity of the latter. ${ }^{59}$ The lack of catalytic activity of $3 \mathrm{c}$ substantiates strong complexation of $\mathbf{1 a}$ to $2 \mathrm{c}$ by the masking of the Lewis acidic empty p-orbital of $1 \mathbf{a}$ without, however, providing evidence specifically for formation of a three-center, four-electron bond. The observation is in agreement with the outcome of the NMR and isothermal titration calorimetric studies, and thus with formation of a stable intermolecular complex.

\section{CONCLUSIONS}

The first experimental evidence of a stable, intermolecular three-center, four-electron tetrel bond complex is presented. We demonstrate that a carbenium ion is converted into a tetrel bond complex by simultaneous overlap of both lobes of the empty p-orbital of the former species with the nonbonding orbitals of two Lewis bases positioned to form a linear threecenter, four-electron $[\mathrm{N}-\mathrm{C}-\mathrm{N}]^{+}$bond. This bond resembles the analogous three-center $[\mathrm{N}-\mathrm{I}-\mathrm{N}]^{+}$halogen bond ${ }^{22}$ in

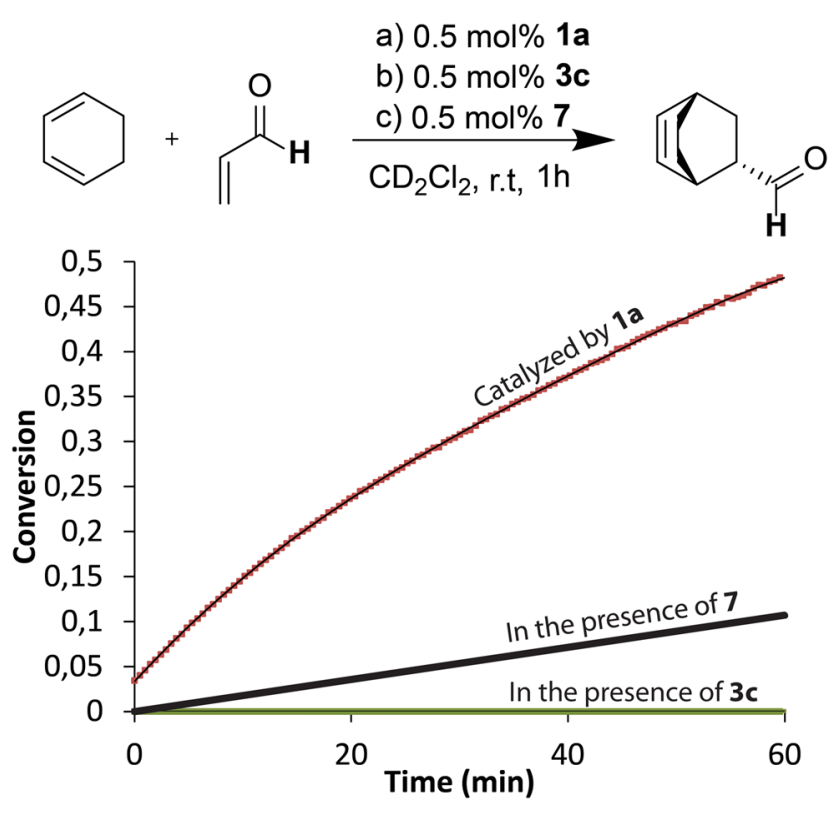

Figure 6. Progress of the Diels-Alder condensation, run under literature conditions, ${ }^{59}$ of 1,3-cyclohexadiene (1.2 equiv) and acrolein ( $1 \mathrm{mmol}$ ) in $\mathrm{CD}_{2} \mathrm{Cl}_{2}$ in the presence of $0.5 \mathrm{~mol} \% 1 \mathrm{a}$ or $3 \mathrm{a}$ was monitored by ${ }^{1} \mathrm{H}$ NMR in an NMR tube at $25{ }^{\circ} \mathrm{C}$ for $1 \mathrm{~h}$. The integral of the signals of the aldehyde proton of the starting material and of the product was used to follow the progress of the reaction. Whereas the reaction catalyzed by $1 \mathbf{a}$ (red) progresses with a second-order rate, the addition of $\mathbf{2 c}$ inhibits it (green) through masking the Lewis acidic $1 \mathrm{a}$ by formation of the tetrel bond complex $3 \mathrm{c}$.

geometry and energy. Thus, formation of the $[\mathrm{N}-\mathrm{C}-\mathrm{N}]^{+}$ complex is associated with $\sim 50 \mathrm{~kJ} / \mathrm{mol}$ change in free energy, as detected by isothermal titration calorimetry. This complex possesses by far the strongest tetrel bond so far reported. ${ }^{60,61}$ Its high stability is corroborated by the inability of the complex to act as a Lewis acid catalyst in a Diels-Alder reaction at room temperature. The observation of a single set of NMR signals even at low temperatures suggests that the complex has a symmetric three-center, four electron bond, whose electron density can be modulated by substitution. However, our observations cannot fully exclude a very low barrier interconversion of asymmetric species in solution. It should be noted that we were unable to confirm the symmetric [N$\mathrm{C}-\mathrm{N}]^{+}$geometry by computation on the DFT level. Further computational studies of the complexes studied herein may thus provide critical insights for theoretical chemistry and, possibly, a more accurate structural interpretation of the NMR and ITC data of $3 \mathbf{a}-\mathbf{f}$.

The formation of a stable three-center, four-electron tetrel bond complex requires the involvement of a bidentate Lewis base whose donors are positioned at an optimal distance and geometry to promote simultaneous overlaps with the unfilled p-orbital of a carbenium ion. Upon use of 2 equiv of an analogous monodentate Lewis base, the carbenium does not form a stable bidentate complex but rather $N$-alkylates the electron donor. It should be noted that the isoelectronic [bis(pyridine)iodine $]^{+}$and [bis(pyridine)bromine $]^{+}$-type halogen-bonded model systems are stable in solution. ${ }^{19,20,22}$ Thus, in contrast with the $[\mathrm{N}-\mathrm{C}-\mathrm{N}]^{+}$complexes, the $[\mathrm{N}-\mathrm{X}-\mathrm{N}]^{+}$ ones do not require the use of a bidentate ligand for thermodynamic stability, highlighting an intriguing difference between halogen and tetrel bonding. The difference in tetrel, 
halogen, and hydrogen bonding is further demonstrated by the fact that $[\mathrm{N}-\mathrm{C}-\mathrm{N}]^{+}$and $[\mathrm{N}-\mathrm{I}-\mathrm{N}]^{+}$complexes are strong, static, and symmetric, whereas the analogous $[\mathrm{N}-\mathrm{H}-\mathrm{N}]^{+}$ complexes are present in solution as mixtures of rapidly interconverting asymmetric tautomers, $[\mathrm{N}-\mathrm{H} \cdots \mathrm{N}]^{+} \rightleftarrows[\mathrm{N} \cdots$ $\mathrm{H}-\mathrm{N}]^{+}$, and lack extra stabilization. ${ }^{15,17}$ Despite its fundamental importance, the three-center, four-electron bond responsible for the stability of $3 \mathbf{a}-\mathbf{f}$ remains an unsolved challenge for bonding theories. ${ }^{45}$ Its further investigation is expected to provide critical insights in numerous fields, not least in synthetic and theoretical chemistry.

The structure of $3 \mathbf{a}-\mathbf{f}$ resembles the transition state geometry of the $S_{N} 2$ reaction, ${ }^{44}$ with the position of the Lewis bases and the carbonium carbon corresponding to that of the linearly arranged nucleophile, the central carbon, and the leaving group in the latter. Similar to the $S_{N} 2$ transition state, the central carbon of these complexes forms a three-center, four electron bond within a trigonal bipyramidal geometry. Therefore, these compounds may be superior model systems for the $S_{\mathrm{N}} 2$ transition state as compared with the previously proposed, isoelectronic three-center, four-electron halogen bonds. $^{23,44}$ Compounds $3 \mathbf{a}-\mathbf{f}$ are thermodynamically stable at room temperature in solution and are easily modifiable through simple synthetic transformations. By an independent variation of the electron density of the apically positioned Lewis bases, the geometry of the $[\mathrm{N}-\mathrm{C}-\mathrm{N}]^{+}$complex ought to be adjustable to reflect various stages of the $S_{N} 2$ reaction. Hence, the presented tetrel bond complexes and their close analogues are expected to be applicable to gain further insights into fundamental reaction mechanisms and chemical bonding theories.

\section{ASSOCIATED CONTENT}

\section{S Supporting Information}

The Supporting Information is available free of charge on the ACS Publications website at DOI: 10.1021/jacs.8b09367.

Details on the synthesis and spectroscopic data for compound identification, and details on the NMR, computational, X-ray diffractometric, and kinetic investigations (PDF)

CIF file for 1-tritylpyridin-1-ium- $\mathrm{BF}_{4}$ (CIF)

\section{AUTHOR INFORMATION}

\section{Corresponding Author}

*mate.erdelyi@kemi.uu.se

\section{ORCID}

Kari Rissanen: 0000-0002-7282-8419

Sandro Keller: 0000-0001-5469-8772

Máté Erdélyi: 0000-0003-0359-5970

Present Address

${ }$ A.-C.C.C.: Astra Zeneca R\&D, Pepparedsleden 1, 43183 Mölndal, Sweden.

\section{Notes}

The authors declare no competing financial interest.

\section{ACKNOWLEDGMENTS}

We thank the Swedish Research Council (ME 2016:03602) for financial support. N.S. thanks the Cluster of Excellence RESOLV (EXC1069) by the Deutsche Forschungsgemeinschaft. K.R. and A.V. kindly acknowledge the Academy of Finland (AV Grant no. 314343) and the University of
Jyväskylä for financial support. J. Franzen and J. Bach of $\mathrm{KTH}$, Sweden, are gratefully acknowledged for instructive discussion on the Lewis acidity of trityl cations. We also acknowledge M. Bedin (Uppsala University) for helpful assistance in the early phase of the project. This study made use of the NMR Uppsala infrastructure, which is funded by the Department of Chemistry-BMC and the Disciplinary Domain of Medicine and Pharmacy at Uppsala University.

\section{REFERENCES}

(1) Arunan, E.; Desiraju, G. R.; Klein, R. A.; Sadlej, J.; Scheiner, S.; Alkorta, I.; Clary, D. C.; Crabtree, R. H.; Dannenberg, J. J.; Hobza, P.; Kjaergaard, H. G.; Legon, A. C.; Mennucci, B.; Nesbitt, D. J. Definition of the Hydrogen Bond (IUPAC Recommendations 2011). Pure Appl. Chem. 2011, 83, 1637.

(2) Desiraju, G. R.; Ho, P. S.; Kloo, L.; Legon, A. C.; Marquardt, R.; Metrangolo, P.; Politzer, P.; Resnati, G.; Rissanen, K. Definition of the Halogen Bond (IUPAC Recommendations 2013). Pure Appl. Chem. 2013, 85, 1711.

(3) Murray, J. S.; Lane, P.; Politzer, P. A Predicted New Type of Directional Noncovalent Interaction. Int. J. Quantum Chem. 2007, 107, 2286.

(4) Ramasubbu, N.; Parthasarathy, R. Stereochemistry of Incipient Electrophilic and Nucleophilic Reactions at Divalent Selenium Center - Electrophilic Nucleophilic Pairing Anisotropic Shape of Se in Se ${ }^{*} \mathrm{Se}$ Interactions. Phosphorus Sulfur Relat. Elem. 1987, 31, 221.

(5) Murray, J. S.; Lane, P.; Clark, T.; Politzer, P. Sigma-Hole Bonding: Molecules Containing Group VI Atoms. J. Mol. Model. 2007, 13, 1033.

(6) Bauza, A.; Frontera, A. Aerogen Bonding Interaction: A New Supramolecular Force? Angew. Chem., Int. Ed. 2015, 54, 7340.

(7) Legon, A. C.; Walker, N. R. What's in a Name? 'Coinage-Metal' Non-Covalent Bonds and Their Definition. Phys. Chem. Chem. Phys. 2018, 20, 19332.

(8) Cavallo, G.; Metrangolo, P.; Pilati, T.; Resnati, G.; Terraneo, G. Naming Interactions from the Electrophilic Site. Cryst. Growth Des. 2014, 14, 2697.

(9) Metrangolo, P.; Resnati, G.; Bryce, D. L.; Desiraju, G. R.; Frontera, A.; Legon, A. C.; Nicotra, F.; Rissanen, K.; Scheiner, S.; Terraneo, G. IUPAC Project 2016-001-2-300: Categorizing Chalcogen, Pnictogen, and Tetrel Bonds, and Other Interactions Involving Groups 14-16 Elements; www.iupac.org/project/2016-001-2-300.

(10) Politzer, P.; Murray, J. S.; Janjic, G. V.; Zaric, S. D. Sigma-Hole Interactions of Covalently-Bonded Nitrogen, Phosphorus and Arsenic: A Survey of Crystal Structures. Crystals 2014, 4, 12.

(11) Crabtree, R. H. Hypervalency, Secondary Bonding and Hydrogen Bonding: Siblings under the Skin. Chem. Soc. Rev. 2017, 46,1720 .

(12) Gilli, G.; Gilli, P. Towards an Unified Hydrogen-Bond Theory. J. Mol. Struct. 2000, 552, 1.

(13) Cleland, W. W. The Low-Barrier Hydrogen Bond in Enzymic Catalysis. Adv. Phys. Org. Chem. 2010, 44, 1.

(14) Cleland, W. W.; Frey, P. A.; Gerlt, J. A. The Low Barrier Hydrogen Bond in Enzymatic Catalysis. J. Biol. Chem. 1998, 273, 25529.

(15) Perrin, C. L. Are Short, Low-Barrier Hydrogen Bonds Unusually Strong? Acc. Chem. Res. 2010, 43, 1550.

(16) Bogle, X. S.; Singleton, D. A. Isotope-Induced Desymmetrization Can Mimic Isotopic Perturbation of Equilibria. On the Symmetry of Bromonium Ions and Hydrogen Bonds. J. Am. Chem. Soc. 2011, 133, 17172.

(17) Perrin, C. L.; Burke, K. D. Variable-Temperature Study of Hydrogen-Bond Symmetry in Cyclohexene-1,2-Dicarboxylate Monoanion in Chloroform-D. J. Am. Chem. Soc. 2014, 136, 4355.

(18) Bedin, M.; Karim, A.; Reitti, M.; Carlsson, A.-C. C.; Topic, F.; Cetina, M.; Pan, F. F.; Havel, V.; Al-Ameri, F.; Sindelar, V.; Rissanen, K.; Grafenstein, J.; Erdelyi, M. Counterion Influence on the N-I-N Halogen Bond. Chem. Sci. 2015, 6, 3746. 
(19) Carlsson, A.-C. C.; Gräfenstein, J.; Budnjo, A.; Laurila, J. L.; Bergquist, J.; Karim, A.; Kleinmaier, R.; Brath, U.; Erdelyi, M. Symmetric Halogen Bonding Is Preferred in Solution. J. Am. Chem. Soc. 2012, 134, 5706.

(20) Carlsson, A.-C. C.; Gräfenstein, J.; Laurila, J. L.; Bergquist, J.; Erdelyi, M. Symmetry of $[\mathrm{N}-\mathrm{X}-\mathrm{N}]^{+}$Halogen Bonds in Solution. Chem. Commun. 2012, 48, 1458.

(21) Carlsson, A.-C. C.; Mehmeti, K.; Uhrbom, M.; Karim, A.; Bedin, M.; Puttreddy, R.; Kleinmaier, R.; Neverov, A. A.; Nekoueishahraki, B.; Gräfenstein, J.; Rissanen, K.; Erdelyi, M. Substituent Effects on the $[\mathrm{N}-\mathrm{I}-\mathrm{N}]^{+}$Halogen Bond. J. Am. Chem. Soc. 2016, 138, 9853.

(22) Hakkert, S. B.; Erdelyi, M. Halogen Bond Symmetry: The N-XN Bond. J. Phys. Org. Chem. 2015, 28, 226.

(23) Karim, A.; Reitti, M.; Carlsson, A.-C. C.; Gräfenstein, J.; Erdelyi, M. The Nature of $[\mathrm{N}-\mathrm{Cl}-\mathrm{N}]^{+}$and $[\mathrm{N}-\mathrm{F}-\mathrm{N}]^{+}$Halogen Bonds in Solution. Chem. Sci. 2014, 5, 3226.

(24) Turunen, L.; Warzoc, U.; Schalley, C. A.; Rissanen, K. Nanosized $\mathrm{I}_{12} \mathrm{~L}_{6}$ Molecular Capsules based on the $\left[\mathrm{N} \cdots \mathrm{I}^{+} \cdots \mathrm{N}\right]$ Halogen Bond. Chem. 2017, 3, 861-869.

(25) Turunen, L.; Peuronen, A.; Forsblom, S.; Kalenius, E.; Lahtinen, M.; Rissanen, K. Tetrameric and Dimeric $\left[\mathrm{Ni}^{+} \mathrm{N}\right]$ Halogen-Bonded Supramolecular Cages. Chem. - Eur. J. 2017, 23, 11714 .

(26) Turunen, L.; Warzok, U.; Puttreddy, R.; Beyeh, N. K.; Schalley, C. A.; Rissanen, K. $[\mathrm{Ni}(+) \mathrm{N}]$ Halogen-Bonded Dimeric Capsules from Tetrakis(3-Pyridyl)Ethylene Cavitands. Angew. Chem., Int. Ed. 2016, 55, 14033.

(27) Mani, D.; Arunan, E. The X-C'” $\mathrm{Y}(\mathrm{X}=\mathrm{O} / \mathrm{F}, \mathrm{Y}=\mathrm{O} / \mathrm{S} / \mathrm{F} / \mathrm{Cl} /$ $\mathrm{Br} / \mathrm{N} / \mathrm{P})$ 'Carbon Bond' and Hydrophobic Interactions. Phys. Chem. Chem. Phys. 2013, 15, 14377.

(28) Southern, S. A.; Bryce, D. L. NMR Investigations of Noncovalent Carbon Tetrel Bonds. Computational Assessment and Initial Experimental Observation. J. Phys. Chem. A 2015, 119, 11891.

(29) Murray, J. S.; Lane, P.; Politzer, P. Expansion of the Sigma-Hole Concept. J. Mol. Model. 2009, 15, 723.

(30) Thomas, S. P.; Pavan, M. S.; Guru Row, T. N. Experimental Evidence for 'Carbon Bonding' in the Solid State from Charge Density Analysis. Chem. Commun. 2014, 50, 49.

(31) Olah, G. A. Stable Carbocations. CXVIII. General Concept and Structure of Carbocations Based on Differentiation of Trivalent (Classical) Carbenium Ions from 3-Center Bound Pentacoordinated or Tetracoordinated (Nonclassical) Carbonium-Ions - Role of Carbocations in Electrophilic Reactions. J. Am. Chem. Soc. 1972, 94, 808.

(32) Grabowski, S. J. Tetrel Bond-Sigma-Hole Bond as a Preliminary Stage of the Sn2 Reaction. Phys. Chem. Chem. Phys. 2014, 16, 1824.

(33) Hojo, M.; Ichi, T.; Shibato, K. Synthesis and Structure of a New Stable Carbocation Stabilized by 2 Neighboring Sulfur-Atoms Dimethyl-9,9-Bis(Methylthio)-1-Fluorenylcarbe-nium Ion. J. Org. Chem. 1985, 50, 1478.

(34) Forbus, T. R.; Martin, J. C. Quest for an Observable Model for the Sn2 Transition-State - Pentavalent Pentacoordinate Carbon. J. Am. Chem. Soc. 1979, 101, 5057.

(35) Forbus, T. R.; Martin, J. C. An Observable Model for the Sn2 Transition-State - Hypervalent Trigonal Bipyramidal Carbon (10-C5). Heteroat. Chem. 1993, 4, 113.

(36) Forbus, T. R.; Kahl, J. L.; Faulkner, L. R.; Martin, J. C. Electrochemical Evidence for Hypervalent (10-C-5) Pentacoordinate Carbon. Heteroat. Chem. 1993, 4, 137.

(37) Akiba, K. Y.; Moriyama, Y.; Mizozoe, M.; Inohara, H.; Nishii, T.; Yamamoto, Y.; Minoura, M.; Hashizume, D.; Iwasaki, F.; Takagi, N.; Ishimura, K.; Nagase, S. Synthesis and Characterization of Stable Hypervalent Carbon Compounds (10-C-5) Bearing a 2,6-Bis(PSubstituted Phenyloxymethyl)Benzene Ligand. J. Am. Chem. Soc. 2005, 127, 5893.

(38) Yamashita, M.; Yamamoto, Y.; Akiba, K. Y.; Hashizume, D.; Iwasaki, F.; Takagi, N.; Nagase, S. Syntheses and Structures of Hypervalent Pentacoordinate Carbon and Boron Compounds Bearing an Anthracene Skeleton-Elucidation of Hypervalent Interaction Based on X-Ray Analysis and DFT Calculation. J. Am. Chem. Soc. 2005, 127, 4354.

(39) Martin, J. C.; Basalay, R. J. Degenerate Interconversions of Sulfonium Ions Involving Intramolecular Nucleophilic Displacement by Neighboring Sulfide Sulfur - Question of an Intermediate in Sn2 Displacement. J. Am. Chem. Soc. 1973, 95, 2572.

(40) Forbus, T. R.; Kahl, J. L.; Faulkner, L. R.; Martin, J. C. Electrochemical Evidence for Hypervalent (10-C-5) Pentacoordinate Carbon. Heteroat. Chem. 1993, 4, 137.

(41) Fernandez, I.; Uggerud, E.; Frenking, G. Stable Pentacoordinate Carbocations: Structure and Bonding. Chem. - Eur. J. 2007, 13, 8620.

(42) Musher, J. I. Chemistry of Hypervalent Molecules. Angew. Chem., Int. Ed. Engl. 1969, 8, 54.

(43) Pimentel, G. C. The Bonding of Trihalide and Bifluoride Ions by the Molecular Orbital Method. J. Chem. Phys. 1951, 19, 446.

(44) Firestone, R. A. Application of Linnett Electronic Theory to Organic Chemistry.4. Sn2 Transition State. J. Org. Chem. 1971, 36, 702.

(45) Landrum, G. A.; Goldberg, N.; Hoffmann, R. Bonding in the Trihalides $\left(\mathrm{X}_{3}^{-}\right)$, Mixed Trihalides $\left(\mathrm{X}_{2} \mathrm{Y}^{-}\right)$and Hydrogen Bihalides $\left(\mathrm{X}_{2} \mathrm{H}^{-}\right)$. The Connection between Hypervalent, Electron-Rich ThreeCenter, Donor-Acceptor and Strong Hydrogen Bonding. J. Chem. Soc., Dalton Trans. 1997, 3605.

(46) Shaik, S. S.; Bar, R. How Important Is Resonance in OrganicSpecies. Nouv. J. Chim. 1984, 8, 411.

(47) Pierrefixe, S. C. A. H.; van Stralen, S. J. M.; van Stralen, J. N. P.; Fonseca Guerra, C.; Bickelhaupt, F. M. Hypervalent Carbon Atom: "Freezing" the $\mathrm{S}_{\mathrm{N}} 2$ Transition State. Angew. Chem., Int. Ed. 2009, 48, 6469.

(48) Hakkert, S. B.; Grafenstein, J.; Erdelyi, M. The 15n Nmr Chemical Shift in the Characterization of Weak Halogen Bonding in Solution. Faraday Discuss. 2017, 203, 333.

(49) Cavallo, G.; Metrangolo, P.; Milani, R.; Pilati, T.; Priimagi, A.; Resnati, G.; Terraneo, G. The Halogen Bond. Chem. Rev. 2016, 116, 2478.

(50) Bah, J.; Naidu, V. R.; Teske, J.; Franzen, J. Carbocations as Lewis Acid Catalysts: Reactivity and Scope. Adv. Synth. Catal. 2015, 357, 148.

(51) Andersson, H.; Carlsson, A.-C. C.; Nekoueishahraki, B.; Brath, U.; Erdelyi, M. Solvent Effects on Nitrogen Chemical Shifts. Annu. Rep. NMR Spectrosc. 2015, 86, 73.

(52) Martin, J. C.; Basalay, R. J. Degenerate Interconversions of Sulfonium Ions Involving Intramolecular Nucleophilic Displacement by Neighboring Sulfide Sulfur - Question of an Intermediate in Sn2 Displacement. J. Am. Chem. Soc. 1973, 95, 2572.

(53) Günther, H. NMR Spectroscopy. Basic Principles, Concepts and Applications in Chemistry, 2nd ed. ed.; John Wiley \& Sons: Eastbourne, U.K., 2001; pp 343-345.

(54) Siehl, H. U. Isotope Effects on NMR-Spectra of Equilibrating Systems. Adv. Phys. Org. Chem. 1987, 23, 63.

(55) Saunders, M.; Kates, M. R. Isotopic Perturbation of Resonance - C-13 Nuclear Magnetic-Resonance Spectra of Deuterated Cyclohexenyl and Cyclopentenyl Cations. J. Am. Chem. Soc. 1977, 99, 8071.

(56) Perrin, C. L.; Kim, Y. J. Symmetry of Metal Chelates. Inorg. Chem. 2000, 39, 3902.

(57) Keller, S.; Vargas, C.; Zhao, H.; Piszczek, G.; Brautigam, C. A.; Schuck, P. High-Precision Isothermal Titration Calorimetry with Automated Peak-Shape Analysis. Anal. Chem. 2012, 84, 5066.

(58) Houtman, J. C.; Brown, P. H.; Bowden, B.; Yamaguchi, H.; Appella, E.; Samelson, L. E.; Schuck, P. Studying Multisite Binary and Ternary Protein Interactions by Global Analysis of Isothermal Titration Calorimetry Data in Sedphat: Application to Adaptor Protein Complexes in Cell Signaling. Protein Sci. 2007, 16, 30.

(59) Bah, J.; Franzen, J. Carbocations as Lewis Acid Catalysts in Diels-Alder and Michael Addition Reactions. Chem. - Eur. J. 2014, 20, 1066. 
(60) Dong, W.; Li, Q.; Scheiner, S. Comparative Strengths of Tetrel, Pnicogen, Chalcogen, and Halogen Bonds and Contributing Factors. Molecules 2018, 23, 1681.

(61) Scheiner, S. Systematic Elucidation of Factors That Influence the Strength of Tetrel Bonds. J. Phys. Chem. A 2017, 121, 5561. 